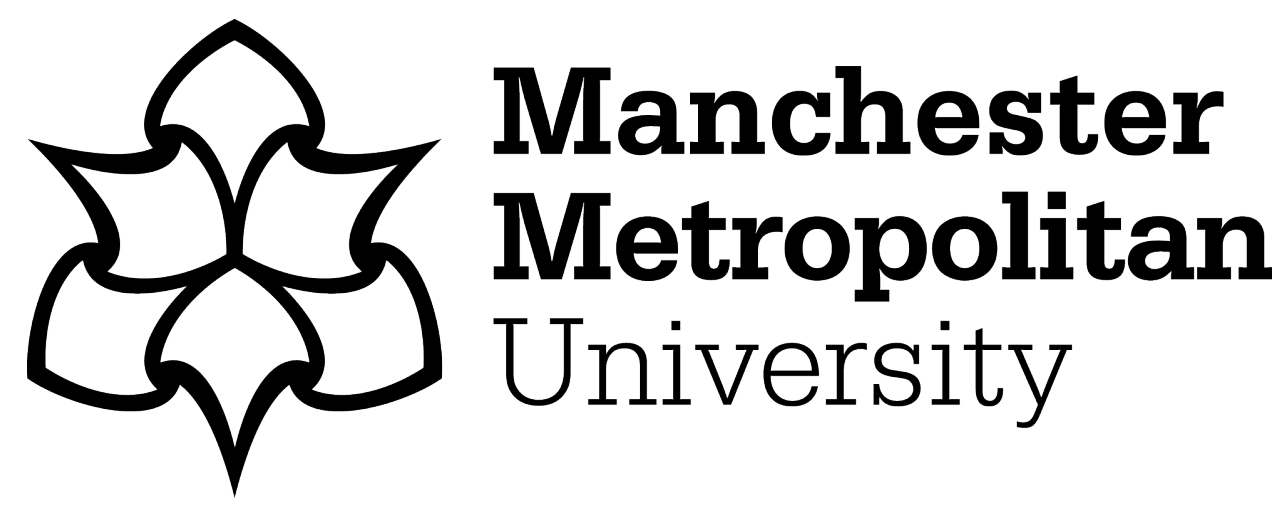

Kennedy, John Paul, Antwis, Rachael E, Preziosi, Richard ORCID logoORCID: https://orcid.org/0000-0003-0468-6655 and Rowntree, Jennifer ORCID logoORCID: https://orcid.org/0000-0001-8249-8057 (2021) Evidence for the genetic similarity rule at an expanding mangrove range limit. American Journal of Botany, 108. pp. 1331-1342. ISSN 0002-9122

Downloaded from: https://e-space.mmu.ac.uk/628339/

Version: Accepted Version

Publisher: Botanical Society of America

DOI: https://doi.org/10.1002/ajb2.1715

Please cite the published version 


\section{Evidence for the genetic similarity rule at an expanding mangrove range limit}

2 John Paul Kennedy ${ }^{1 *}$, Rachael E. Antwis ${ }^{2}$, Richard F. Preziosi ${ }^{1}$, and Jennifer K. Rowntree ${ }^{1}$

$3{ }^{1}$ Ecology and Environment Research Centre, Department of Natural Sciences, Faculty of Science

4 and Engineering, Manchester Metropolitan University, Manchester, UK

$5 \quad{ }^{2}$ School of Science, Engineering and Environment, University of Salford, Salford, UK

$6 \quad$ Corresponding author.

$7 \quad$ E-mail address: john.p.kennedy@stu.mmu.ac.uk; kennedy3jp@gmail.com

8 Running head: Community genetics at a mangrove range limit

9

10 Citation: Kennedy, J. P., R. E. Antwis, R. F. Preziosi, and J. K. Rowntree. 2021. Evidence for

11 the genetic similarity rule at an expanding mangrove range limit. American Journal of Botany

12 108(8): 1331-1342.

13 DOI: https://doi.org/10.1002/ajb2.1715 
14 PREMISE: Host-plant genetic variation can shape associated communities of organisms. These community-genetic effects include (1) genetically-similar hosts harbouring similar associated communities (i.e., the genetic similarity rule) and (2) host-plant heterozygosity increasing

17 associated community diversity. Community-genetic effects are predicted to be less prominent in plant systems with limited genetic variation, such as those at distributional range limits. Yet, 19 empirical evidence from such systems is limited.

METHODS: We sampled a natural population of a mangrove foundation species (Avicennia

21 germinans) at an expanding range limit in Florida, USA. We measured genetic variation within

22 and among 40 host trees with 24 nuclear microsatellite loci and characterised their foliar

23 endophytic fungal communities with ITS1 gene amplicon sequencing. We evaluated

24 relationships among host-tree genetic variation, host-tree spatial location, and the associated 25 fungal communities.

RESULTS: Genetic diversity was low across all host trees (mean: 2.6 alleles per locus) and

27 associated fungal communities were relatively homogeneous (five sequence variants represented $78 \%$ of all reads). We found: (1) genetically-similar host trees harboured similar fungal 29 communities, with no detectable effect of inter-host geographic distance. (2) Host-tree heterozygosity had no detectable effect, while host-tree absolute spatial location affected 31 community alpha diversity.

32 CONCLUSIONS: This research supports the genetic similarity rule within a range limit 33 population and helps broaden the current scope of community genetics theory by demonstrating 34 that community-genetic effects can occur even at expanding distributional limits where host35 plant genetic variation may be limited. Our findings also provide the first documentation of 36 community-genetic effects in a natural mangrove system. 
KEY WORDS

associated communities; Avicennia germinans; black mangrove; community genetics;

40 endophytic fungi; foundation species; intra-individual heterozygosity; plant genetic variation

\section{INTRODUCTION}

44 Intraspecific diversity can shape the ecological dynamics of communities and entire ecosystems

45 (Raffard et al., 2019). For instance, a central principle of community genetics is that genetic

46 variation within a host plant can influence the structure and diversity of associated communities

47 of organisms (Whitham et al., 2003). Empirical evidence of community-genetic effects is found

48 across diverse systems, including terrestrial forests with low (Whitham et al., 2006) and high

49 (Zytynska et al., 2011) species diversity, agricultural landscapes (Stevenson et al., 2017), and

50 aquatic systems (Jormalainen et al., 2017). This pattern may be most prominent in systems

51 dominated by a limited number of plant foundation species (Whitham et al., 2006), which define

52 ecosystems with their physical structure and provide resources that directly influence diverse

53 community assemblages (Ellison et al., 2005).

54 Community-genetic effects are measured both in terms of host-plant genetic similarity and 55 diversity, plus spatial effects need to also be considered. First, genetically-similar host plants 56 may harbour similar associated communities, a pattern known as the genetic similarity rule 57 (Bangert, Allan, et al., 2006; Bangert, Turek, et al., 2006; Barbour et al., 2009; Kagiya et al., 58 2018). Second, increased genetic diversity at the population level may lead to concomitant 59 increases in associated species diversity (Wimp et al., 2004; Crutsinger et al., 2006; Johnson et 
60 al., 2006). Similar patterns are also found when considering the genetic diversity of individual

61 host plants (i.e., heterozygosity) (Tovar-Sánchez et al., 2013; Valencia-Cuevas et al., 2018). This

62 extension of community genetics theory is in line with extensive research on the link between

63 intra-individual heterozygosity and fitness (reviews by Hansson and Westerberg, 2002; Szulkin

64 et al., 2010). Lastly, in addition to host genetic variation, the spatial context of host plants,

65 including their relative position in relation to neighbouring conspecifics and variation in

66 environmental conditions, needs to also be considered as spatial effects can prove more

67 influential (Tack et al., 2010; Gossner et al., 2015; Barbour et al., 2019; but see Bangert, Allan,

68 et al., 2006; Lamit et al., 2015).

69 Community-genetic effects may also vary with the extent of genetic variation present in the

70 host population. Plant systems with limited genetic variation are predicted to exhibit less

71 prominent effects and, instead, environmental variation will exhibit a stronger effect on

72 associated community structure (Bangert, Turek, et al., 2006). However, only one study has

73 provided empirical evidence from such systems. Pohjanmies et al. (2015) documented that

74 genetic variation within a tree foundation species correlates with the structure and diversity of

75 associated herbivore communities at a distributional range limit. Range limits may exhibit

76 limited genetic variation (Pironon et al., 2017) and are shifting for many species with

77 anthropogenic climate change (Pecl et al., 2017). Further assessments of relationships between

78 host-plant genetic variation and associated communities at range limits, especially those where

79 foundation species are undergoing climate-driven range shifts, could help broaden the current

80 scope of community genetics theory and provide insights into the ecological and evolutionary

81 processes shaping these dynamic systems. 
In this study, we evaluated relationships between genetic variation within a mangrove foundation species at its expanding distributional range limit and the structure and diversity of associated foliar endophytic fungal communities. Mangroves are (sub)tropical, intertidal woody

85 plants that provide vital ecosystem services to coastal habitats worldwide (Lee et al., 2014).

86 Mangrove forests consist of relatively few tree species (Alongi, 2009) and, as such, intraspecific

87 differences may be particularly influential in shaping ecological dynamics in these systems

88 (Farnsworth, 1998). Numbers of mangrove species are further reduced towards climate-sensitive,

89 poleward range limits where generally only one predominant species exists (Osland et al., 2017)

90 and often genetic variation is limited (e.g., Pil et al., 2011; De Ryck et al., 2016; Kennedy et al.,

91 2017; Binks et al., 2019; Ochoa-Zavala et al., 2019).

Mangrove systems harbour numerous associated communities of both terrestrial and marine origin (Nagelkerken et al., 2008), including diverse fungal communities found on or within multiple mangrove tissues (e.g., Gilbert et al., 2002; Arfi et al., 2012; de Souza Sebastianes et al., 2013; Lee et al., 2019). Fungal endophytes are ubiquitous inhabitants within plant tissues, obtain 96 shelter and nutrition from their host plant, and may influence plant health and function (Arnold, 97 2007; Porras-Alfaro and Bayman, 2011). Endophytic fungi in leaves and twigs vary among host 98 genotypes of diverse plant species (Elamo et al., 1999; Pan et al., 2008; Lamit et al., 2014;

99 Griffiths et al., 2020); however, whether intraspecific genetic differences among mangrove host 100 101 unanswered.

We sampled a natural population of neotropical black mangrove (Avicennia germinans) at a 103 northern range limit on the Atlantic coast of Florida, USA. At this range limit, A. germinans is 104 the predominant mangrove species (Lonard et al., 2017), exists as discrete patches within a 
105 landscape dominated by salt-marsh vegetation (Kangas and Lugo, 1990), and exhibits reduced 106 genetic variation (Kennedy, Preziosi, et al., 2020) and elevated levels of self-fertilisation

107 (Kennedy et al., 2021). A lack of extreme freeze events for several decades has been linked to $A$. 108 germinans proliferation (Cavanaugh et al., 2014; Osland et al., 2018) and further expansion is 109 forecast with climate change (Cavanaugh et al., 2015, 2019), which may have wide-reaching 110 effects on these coastal ecosystems (Kelleway et al., 2017). We genotyped A. germinans host 111 trees with 24 nuclear microsatellite loci, characterised communities of endophytic fungi in their 112 leaves with ITS1 gene amplicon sequencing, and accounted for potential spatial effects with 113 host-tree GPS coordinates and inter-host geographic distances. We asked: (1) Do inter-host 114 genetic similarity and inter-host geographic distance correlate with similarity among associated 115 endophytic fungal communities? (2) Do host-tree heterozygosity and host-tree absolute spatial 116 location correlate with alpha diversity of the associated endophytic fungal community?

118 MATERIALS AND METHODS

119 Study design

120 On 09 October 2017, we sampled from and collected GPS coordinates for 40 mature $A$.

121 germinans trees, all approximately the same height $(\sim 2 \mathrm{~m})$, at a single collection site $(29.7284,-$ 122 81.2425) near the Atlantic Florida range limit. Mangrove area has progressively increased for 123 several decades at this site (Rodriguez et al., 2016) which is flanked by a brackish lagoon to the 124 west and a fringe of terrestrial hammock forest to the east. Salinity during this time of the year 125 (Sept-Nov) increases from west to east along the site (38 to $67 \%$ ), then decreases adjacent to 126 the terrestrial fringe (40 \%o) (Guana Tolomato Matanzas National Estuarine Research Reserve, 127 unpublished data; Fig. 1). Our sampling area covered $\sim 0.1 \mathrm{~km}^{2}$, which included most of the total 
128 spatial extent of this $A$. germinans population, with a minimum inter-tree distance of $11 \mathrm{~m}$ and a 129 maximum distance of $528 \mathrm{~m}$ (Fig. 1). For each tree, we sampled a total of three undamaged 130 leaves, each from the first fully mature leaf pair on branches located in direct sunlight. We 131 collected these leaves (generally the third leaf pair) to standardise leaf age and exposure to 132 sunlight, both of which can influence fungal community structure (Koide et al., 2017;

133 Younginger and Ballhorn, 2017). We placed leaves from each tree into separate, labelled plastic 134 bags and stored them in a portable cooler with an ice pack during fieldwork and subsequent 135 transport to the laboratory.

\section{Sample processing and DNA isolation}

138 Leaves were kept on ice and processed within 24 hours of sampling. We rinsed individual leaves 139 under running tap water for $30 \mathrm{sec}$, then surface sterilised with sequential immersion in $95 \%$ 140 ethanol for 10 seconds, $0.5 \%$ bleach for 2 minutes, and $70 \%$ ethanol for 2 minutes under a sterile 141 hood (U'Ren et al., 2014). We allowed leaves to air dry and then used sterilised surgical blades 142 to cut $\sim 5 \mathrm{~mm}$ x $5 \mathrm{~mm}$ sections from the middle of each leaf at both sides of the midvein. We 143 combined the cut sections from each of the three leaves per tree into a single microcentrifuge 144 tube and isolated genomic DNA with the DNeasy Plant Mini Kit (Qiagen, Hilden, Germany) 145 following the standard protocol, with an extended incubation of 45 minutes. We also included 146 two extraction blanks (negative controls) during this process. We quantified DNA extracts on a

147 Qubit 2.0 Fluorometer (ThermoFisher Scientific, Waltham, Massachusetts, USA) and created 148 standardised aliquots of $35 \mathrm{ng} / \mathrm{uL}$ to be used for both host-tree genotyping and fungal community 149 sequencing. We stored DNA aliquots at $-20^{\circ} \mathrm{C}$ until further processing. 


\section{$151 \quad$ Host-tree genotyping}

152 We genotyped host trees at 32 nuclear microsatellite loci. Of this total, 12 loci were previously

153 developed (Nettel et al., 2005; Cerón-Souza et al., 2006, 2012; Mori et al., 2010) and genotyped

154 following the protocol outlined in Kennedy, Preziosi, et al. (2020). The remaining 20 loci were

155 more recently developed (Craig, Feller, et al., 2020) and genotyped following the author's

156 protocol. We performed PCR on a Prime thermal cycler (Techne, Straffordshire, UK), analysed

157 fragments on an Applied Biosystems 3730 DNA Analyzer (Applied Biosystems, Foster City,

158 California, USA) with LIZ 500 size standard, and scored alleles in the R-package Fragman

159 (Covarrubias-Pazaran et al., 2016). We evaluated the presence of null alleles in MICRO-

CHECKER 2.2.3 (van Oosterhout et al., 2004) and randomly amplified and genotyped 10\% of 161 our DNA samples $(\mathrm{n}=4)$ a second time to estimate a study error rate (Bonin et al., 2004). We

162 tested for linkage disequilibrium and deviations from Hardy-Weinberg equilibrium, and

163 calculated the number of alleles and observed and expected heterozygosity per locus in FSTAT $164 \quad$ 2.9.3.2 (Goudet, 2002).

165 We calculated five measures of host-tree heterozygosity (i.e., proportion of heterozygous 166 loci, observed heterozygosity, expected heterozygosity, internal relatedness, homozygosity by

167 loci) for each of the 40 host trees with the R-function GENHET (Coulon, 2010). We also

168 manually calculated the number of alleles within the multi-locus genotype of each host tree. All

169 six measures were highly correlated (Pearson's correlation, $r=0.96-1.0, p<0.001)$. Hence, we

170 present results only for homozygosity by loci (HL), an index that considers allelic variability at

171 each locus to estimate heterozygosity and, based on simulations, correlates better than other

172 measures with genome-wide heterozygosity (Aparicio et al., 2006). As this index varies from 0

173 (all loci are heterozygous) to 1 (all loci are homozygous), we used 1 - HL for statistical analyses 
174 to provide more intuitive results (i.e., higher values represent higher heterozygosity). To evaluate 175 genetic similarity, we calculated pairwise inter-individual genetic distances (as outlined in

176 Smouse and Peakall, 1999) and geographic distances among the 40 host trees in GenAlEx 6.5

177 (Peakall and Smouse, 2012).

179 Associated fungal community sequencing

180 We performed ITS gene amplicon library preparation and sequencing at the University of

181 Salford, UK. Fungal DNA was amplified at the ITS 1F-2 gene (White et al., 1990) with modified 182 versions of the ITS1F (5'-CTT GGT CAT TTA GAG GAA GTA A-3') and ITS2 (5'-GCT 183 GCG TTC TTC ATC GAT GC -3') primer set that included Illumina adapters, a linker, and 184 unique barcodes (see Smith and Peay, 2014) as outlined in Griffiths et al. (2020). PCR products 185 for our samples and those of 80 additional fungal samples, which consisted of ITS1 gene 186 amplicons used for an unrelated study, were then pooled to equimolar concentrations. ITS1 gene 187 amplicon sequencing was performed using paired-end reads with an Illumina v3 ( 2 x $300 \mathrm{bp})$ 188 cartridge on an Illumina MiSeq (Illumina, San Diego, California, USA). Negative (extraction 189 blanks) and positive (synthetic mock community with 12 mock isolates; Palmer et al., 2018) 190 controls were also included in the sequence run.

191 We removed adaptor and primer sites from the ITS1 gene sequence data with cutadapt v2.4 192 (Martin, 2011), and performed all subsequent data processing and calculations in R v3.6.0 (R 193 Core Team, 2020). A total of 275,829 raw sequences across our 40 samples were generated. We 194 used the R-package DADA2 1.12.1 (Callahan et al., 2016) with default pipelines to perform 195 quality filtering and taxonomic assignment with the UNITE v8.0 database (UNITE Community, 196 2019). Here, we analysed only forward sequence reads because lower quality and quantity of 
reverse reads resulted in a nearly $50 \%$ reduction in total sequence reads after quality filtering of the assembled paired-end reads (Appendix S1a, see the Supplementary Data with this article). Discarding low-quality reverse reads is a common strategy that often provides better results than assembled paired-end reads (Nguyen et al., 2015; Pauvert et al., 2019). One chimera was removed. We then removed amplicon sequence variants (ASVs) with $<100$ reads across all samples as a conservative approach to deal with potential artifacts of high-throughput sequencing (Pauvert et al., 2019). Modal contig length was 225 bp (range: $153-251$ bp). No contaminants were identified in the first negative control, and one ASV was identified in the second negative control, but was not found in other samples. All 12 expected ASVs were identified in the synthetic mock community. We did not further trim forward reads, we manually checked whether ASVs with identical taxonomic assignments were indeed unique sequences (i.e., did not simply vary at the start or end of the sequence), and all ASVs assigned as unidentified fungi were further checked with default blastn analyses on the UNITE website (Nilsson et al., 2019). We removed all ASVs that corresponded to the host-tree species (A. germinans), which included $64 \%$ of all sequence reads, and all additional unidentified fungi had significant alignments with public fungal ITS sequences (e-values $=1 \mathrm{e}^{-13}-4 \mathrm{e}^{-88}$ ). The resulting data set consisted of 64,308 reads across 40 samples, with a median of 748 reads per sample (range: $104-9,314$ ).

We exported the ASV table, taxonomy table, and sample identifications to the R-package phyloseq 1.28.0 (McMurdie and Holmes, 2013) for the following calculations. We calculated alpha diversity of fungal communities with Hill numbers (Hill, 1973) at the scales of $q=0$ (species richness), $\mathrm{q}=1$ (exponential of Shannon index), and $\mathrm{q}=2$ (inverse of Simpson index), which represent the effective number of species and put more weight on abundant species as the value of q increases (Chao et al., 2014). We performed these calculations with the raw count data 
220 rarefied to a standardised number of reads equal to the sample with the lowest read count (104

221 reads; see Appendix S2a). Although read counts were limited for certain samples, asymptotes

222 were reached in all rarefaction curves with few rank-order changes among samples past this

223 lowest read count (Appendix S2a). As such, our sampling effort seems to have captured most

224 diversity within these samples. Random sampling to generate rarefied counts can add noise to a

225 data set and undermine the performance of downstream methods (McMurdie and Holmes, 2014);

226 therefore, we also performed alpha diversity calculations and the subsequent statistical analyses

227 with the raw count data and results were equivalent to those presented here (Appendix S1b). To

228 evaluate community dissimilarity (beta diversity), we calculated Bray-Curtis dissimilarity with

229 the raw count data converted to relative abundances. We also calculated Aitchison distance by

230 centred log-ratio (clr) transforming the raw count data with the R-package microbiome (Lahti et

231 al., 2017) and then calculating pairwise Euclidean distances in phyloseq 1.28.0 (McMurdie and

232 Holmes, 2013). Aitchison distance accounts for the compositional nature of high-throughput

233 sequence data, which makes this measure more appropriate than many standard measures (Gloor

234 et al., 2017; Quinn et al., 2018).

235

236 Statistical analyses

237 We performed all statistical analyses in R v3.6.0 (R Core Team, 2020). To address our first 238 question, we tested for an effect of inter-host genetic distance and a relative spatial effect of 239 inter-host geographic distance on dissimilarity among associated endophytic fungal communities 240 across all samples with ranked Mantel tests of correlation. As spatial effects may not be linear

241 (Diniz-Filho et al., 2013; Legendre et al., 2015), we also performed multivariate Mantel 242 correlograms to assess these patterns at five discrete distance classes. All analyses were 
243 performed in the R-package ecodist (Goslee and Urban, 2007). Significance for each analysis

244 was determined with $10^{4}$ permutations, and p-values for correlograms were adjusted for multiple

245 comparisons with a false discovery rate correction method using the R-function p.adjust. For

246 both Mantel tests and Mantel correlograms, we first tested for a relationship between the two

247 predictor variables (i.e., inter-host genetic distance and inter-host geographic distance), then

248 performed separate tests between fungal community dissimilarity and each of the two predictor

249 variables, and finally performed partial analyses between fungal community dissimilarity and

250 inter-host genetic distance, while controlling for inter-host geographic distance.

251 To address our second question, we tested for an effect of host-tree heterozygosity and an

252 absolute spatial effect of host-tree spatial location on the alpha diversity of associated endophytic

253 fungal communities with multiple linear regressions. We fitted three additive models, with alpha

254 diversity of fungal communities at each Hill number $(q=0,1,2)$ as the response variable and

255 heterozygosity, longitude, and latitude of each host tree as predictor variables. We also tested full

256 models and subsets with interactions among two of the three predictor variables, but none of

257 these interactions proved statistically significant and none of these models provided better fits

258 based on the Bayesian Information Criterion (BIC; Schwarz, 1978). Hill numbers at $\mathrm{q}=1$ and $\mathrm{q}=2$

259 were natural log-transformed to meet the statistical assumption of normality, and we centred and

260 scaled the predictor variables to standardise regression coefficients.

261

262 RESULTS

263 Host-tree genotyping

264 We discarded seven of the 32 nuclear microsatellite loci that were monomorphic across all

265 samples, and discarded another locus that proved difficult to score. Our final host-tree genotypes 
266 included 24 loci (Appendix S1c) with no missing data, and all 40 host-tree genotypes were

267 unique. We found no evidence for null alleles and each of the four samples that were amplified

268 and genotyped a second time produced consistent multi-locus genotypes. We found no evidence

269 for linkage disequilibrium or deviations from Hardy-Weinberg equilibrium. Genetic variation

270 was low across the 40 host trees, with $2.6 \pm 1.4$ (SD) alleles per locus and expected

271 heterozygosity of $0.37 \pm 0.20$ (Appendix S1c). Host-tree heterozygosity ( $1-\mathrm{HL}$ ) ranged from

2720.06 to 0.81 (mean: $0.45 \pm 0.15$ ).

273

274 Associated fungal community sequencing

275 A total of 49 amplicon sequence variants (ASVs) were identified across the 40 host trees. Most

276 ASVs were assigned to the phylum Ascomycota (35 of 49 ASVs, 87\% of all reads) and 11\% of

277 all reads were assigned only to the level of kingdom Fungi (Appendix S2b). Less than half (47\%)

278 of all reads were assigned class level taxonomy, with the class Dothideomycetes as the most

279 common (28\% of all reads; Appendix S2c). The endophytic fungal community was relatively

280 homogeneous, with one ASV (assigned taxonomy only to the level of phylum Ascomycota)

281 representing $41 \%$ of all reads (Appendix S1d). The five most abundant ASVs represented $78 \%$

282 of all reads, and subsequent ASVs each represented $\leq 2 \%$ of all reads (Appendix S1d). Alpha

283 diversity of fungal communities across the 40 host trees at $q=0$ (species richness) was $4.0 \pm 1.7$

284 (SD), at $\mathrm{q}=1$ (exponential of Shannon index) was $2.8 \pm 1.2$, and at $\mathrm{q}=2$ (inverse of Simpson

285 index) was $2.5 \pm 1.1$.

286

287 Associated fungal community structure correlates with host-tree genetics 
288 Genetically-similar host trees harboured similar associated fungal communities, with no 289 detectable relative spatial effect of geographic distance among host trees both across all samples 290 (Mantel tests) and at five distance classes (Mantel correlograms) (Fig. 2). For Mantel tests, the 291 predictor variables (i.e., inter-host genetic distance and inter-host geographic distance) exhibited 292 no relationship (Mantel correlation, $\mathrm{r}_{\mathrm{M}}=0.05, \mathrm{p}=0.181$; Appendix $\mathrm{S} 2 \mathrm{~d}$ ). Fungal community 293 (Bray-Curtis) dissimilarity exhibited a weak, but statistically significant positive relationship 294 with inter-host genetic distance $\left(r_{M}=0.26, p=0.002\right)$, and no relationship with inter-host 295 geographic distance $\left(r_{M}=0.06, p=0.164\right)($ Fig. 2a, b). Accounting for inter-host geographic 296 distance did not impact the relationship with inter-host genetic distance (partial $\mathrm{r}_{\mathrm{M}}=0.26, \mathrm{p}=$ 297 0.002). Community dissimilarity measured with Aitchison distance provided equivalent results 298 (inter-host genetic distance: $r_{M}=0.16, p=0.041$; inter-host geographic distance: $r_{M}=0.05, p=$ 299 0.188) (Fig. 2e, f), with a weaker relationship with inter-host genetic distance (partial $\mathrm{r}_{\mathrm{M}}=0.16$, $300 \mathrm{p}=0.043)$.

301 Mantel correlogram results were equivalent to those of the Mantel tests, with no 302 relationships between predictor variables $\left(\mathrm{r}_{\mathrm{M}}=-0.07-0.07, \mathrm{p} \geq 0.568\right.$; Appendix $\left.\mathrm{S} 2 \mathrm{~d}\right)$, and 303 community (Bray-Curtis) dissimilarity exhibited statistically significant positive relationships 304 with the first two genetic distance classes $\left(r_{M}=0.16, p=0.002 ; r_{M}=0.14, p=0.050\right.$; 305 respectively), a statistically significant negative relationship with the fourth genetic distance 306 class $\left(r_{M}=-0.16, p=0.008\right)$, and no relationships with inter-host geographic distance classes $\left(r_{M}\right.$ $307=-0.06-0.03, p \geq 0.810)($ Fig. $2 c, d)$. Accounting for inter-host geographic distances did not 308 impact these relationships with inter-host genetic distance classes, except for the second genetic 309 distance class that was now statistically non-significant $(\mathrm{p}=0.090)$ (Appendix S2e). Community 310 dissimilarity measured with Aitchison distance provided equivalent results (Fig. 2g, h), with 
311 weaker relationships with inter-host genetic distance classes that were statistically significant at

312 only the first genetic distance class $\left(\mathrm{r}_{\mathrm{M}}=0.13, \mathrm{p}=0.027\right)$. Accounting for inter-host geographic

313 distances did not impact these relationships (Appendix S2e).

\section{Associated fungal community diversity correlates with host-tree spatial location}

316 Host-tree heterozygosity had no detectable effect on the alpha diversity of associated endophytic 317 fungal communities. Instead, the absolute spatial location of host trees affected these associated 318 fungal communities. Additive models explained limited variation in the alpha diversity of fungal 319 communities at each of the three Hill numbers. The model for $\mathrm{q}=0$ was not statistically

320 significant $\left(\mathrm{F}_{3,36}=1.7, \mathrm{p}=0.195\right.$, adjusted $\left.\mathrm{r}^{2}=0.05\right)$ and models for $\mathrm{q}=1\left(\mathrm{~F}_{3,36}=3.1, \mathrm{p}=0.038\right.$, 321 adjusted $\left.\mathrm{r}^{2}=0.14\right)$ and $\mathrm{q}=2\left(\mathrm{~F}_{3,36}=3.4, \mathrm{p}=0.027\right.$, adjusted $\left.\mathrm{r}^{2}=0.16\right)$ were marginally

322 significant. Longitude was the only predictor variable to exhibit a significant partial regression 323 slope (for full model breakdown see Table 1). This increase in fungal community alpha diversity 324 with increased longitude (i.e., from the brackish lagoon to the landward margin) was statistically 325 significant at each of the three Hill numbers $(\mathrm{p}=0.043,0.009,0.009$, respectively; Table 1). Yet, 326 instead of a systematic increase, these effects seemed to be shaped primarily by the fact that 327 highest fungal alpha diversity was observed within trees closest to the landward margin (Fig. 3).

\section{DISCUSSION}

330 Community-genetic effects are predicted to be less prominent in plant systems with limited 331 genetic variation, such as those at distributional range limits. Yet, empirical evidence from such 332 systems is limited. Here, at the scale of an expanding range limit population of a mangrove 333 foundation species (Avicennia germinans), we found evidence for the genetic similarity rule 
334 whereby genetically-similar host trees harboured similar associated endophytic fungal

335 communities. In contrast, we found no detectable effect of host-tree heterozygosity on fungal

336 community alpha diversity. This research demonstrates that community-genetic effects can occur

337 even at expanding distributional limits where host-plant genetic variation may be limited, and

338 provides the first documentation of these effects in a natural mangrove system.

Genetically-similar mangrove hosts harbouring similar endophytic fungal communities, with no detectable relative spatial effect, may be explained by the mode of fungal transmission and/or

341 biotic filtering dictated by the physiology and anatomy of the host plant (Ricks and Koide,

342 2019). Horizontal transmission via airborne fungal spores is commonly observed in woody

343 plants (Arnold and Herre, 2003 and citations within), although vertical transmission from parent

344 tree to seed is also possible (e.g., Vega et al., 2010). Our studied species (A. germinans) produces

345 cryptoviviparous propagules (i.e., embryos emerge from the seed coat, but remain within the

346 fruit until abscission from maternal trees), with varying degrees of vivipary across many

347 mangrove species (Tomlinson, 1986). This form of reproduction, where developing propagules

348 remain attached to maternal trees for extended periods may lead to a greater contribution of 349 fungal transfer from parent to offspring. Consistent with this hypothesis, endophytic fungi (Lee 350 et al., 2019) and bacteria (Soldan et al., 2019) are found within surface-sterilised 351 cryptoviviparous mangrove propagules collected directly from maternal trees. Host physiology 352 may also dampen horizontal transfer in A. germinans as salt excretion through leaf glands (a 353 mechanism to tolerate salt stress) can reduce foliar fungal colonisation (Gilbert et al., 2002). 354 Fungal communities in trees also vary with differences in phenotypic leaf traits, such as internal 355 chemistry and surface characteristics (Valkama et al., 2005; Kembel and Mueller, 2014). 356 Additional research that compares fungal endophytes in both A. germinans maternal trees and 
357 their offspring, with parallel leaf trait assessments, could evaluate the relative influence of fungal

358 transmission mode and biotic filtering in shaping these associated communities.

359 We did not detect an effect of host-tree heterozygosity on fungal community alpha diversity.

360 Instead, we found that alpha diversity varied with the absolute spatial location of host trees.

361 Increased host-tree heterozygosity can lead to greater growth rates (Charlesworth and Willis,

362 2009) and greater foliar phytochemical diversity (Campbell et al., 2013), factors that may

363 underlie increases in associated herbivore community alpha diversity observed elsewhere

364 (Tovar-Sánchez et al., 2013; Valencia-Cuevas et al., 2018). We suggest that, within this

365 mangrove population, the limited genetic variation present across host trees may not translate

366 into large enough variation in host-tree phenotypic traits that would augment the alpha diversity

367 of these associated communities. Rather, community alpha diversity increased with longitude

368 across our collection site (i.e., from the brackish lagoon to the landward margin), an absolute

369 spatial effect seemingly shaped by the fact that highest alpha diversity was observed within trees

370 closest to the landward margin. Soil salinity increases with longitude across the site, but then

371 declines at this landward margin adjacent to a fringe of terrestrial forest (Fig. 1). Salinity

372 differences can impact fungal communities associated with the A. germinans rhizosphere

373 (Vanegas et al., 2019), but their effect on foliar fungal communities remains to be formally

374 tested. Higher soil salinity closer to the centre of the collection site will demand greater salt

375 excretion through A. germinans leaf glands (Sobrado and Greaves, 2000; Suárez and Medina,

376 2008) that may further diminish foliar fungal colonisation in this species (Gilbert et al., 2002). In

377 addition, as mangrove leaves may contain fungi predominately from terrestrial sources (Lee et

378 al., 2019, 2020), the fringe of terrestrial forest is presumably a reservoir of unique fungal

379 diversity. Therefore, within the mangrove population studied here, trees located nearest to this 
380 landward margin may harbour slightly more diverse fungal communities than conspecifics

381 elsewhere due to both reduced soil salinity and proximity to additional fungal sources. Whether

382 this pattern extends to additional mangrove populations remains to be tested.

Pohjanmies et al. (2015), with their research at a distributional range limit, provided the first

384 empirical evidence of community-genetic effects within a plant system with limited genetic

385 variation. Our documentation of the genetic similarity rule at a mangrove range limit, where host

386 trees possessed very limited genetic variation (on average, 2.6 alleles per locus), adds further

387 support to these previous findings and strengthens the argument that correlations between genetic

388 variation within foundation species and the dynamics of associated communities can occur even

389 at distributional limits that may be genetically depauperate. These correlations, however, will

390 ultimately depend on the strength of the community-genetic effect relative to the degree of

391 environmental variation and how this relationship varies with spatial scale (Bangert et al., 2008).

392 Both Pohjanmies et al. (2015) and our study assessed correlations between plant foundation

393 species and their associated communities within single range limit populations. Environmental

394 variation will inherently be small at this local scale compared to that across broader spatial scales

395 where community-genetic effects may be less influential (Hughes and Stachowicz, 2009; Tack et

396 al., 2010; Gossner et al., 2015; but see Bangert, Allan, et al., 2006; Davies et al., 2014; Lamit et

397 al., 2015). Spatial effects on foliar endophytic fungal communities in mangroves are evident

398 across greater geographic distances (Lee et al., 2019, 2020). As such, the relationship between

399 mangrove host-tree genetic variation and associated fungal communities documented here may

400 vary depending on the spatial extent under consideration and warrants additional research.

$401 \quad$ Although we sampled a relatively small spatial area, this is the scale at which species

402 expansion occurs as small isolated populations become colonised and begin to proliferate. This 
process is particularly evident at the Atlantic Florida A. germinans range limit where initial colonisation may consist of a single individual (Kennedy, Dangremond, et al., 2020), and for the population studied here which has increased from only about $10 \%$ to $45 \%$ mangrove cover over the past several decades (Rodriguez et al., 2016). In this context, our research demonstrates that community-genetic effects can occur across the spatial extent of an expanding range limit population, with potential implications for host fitness and population resilience as endophytic fungi can vary greatly in function within plant hosts from latent pathogens to mutualistic symbionts (Porras-Alfaro and Bayman, 2011). Symbioses with endophytic fungi can contribute to plant adaptation to high-stress environments (Rodriguez et al., 2004), with evidence that variation in soil fungal communities can influence the fitness and susceptibility of $A$. germinans to cold stress (Chen et al., 2020), although fungal infections can reduce recruitment (Devaney et al., 2017). We documented a correlation between mangrove host-tree genetics and fungal community differences, but does this relationship generate variation in stress tolerance among mangrove hosts? If so, this insight could broaden the current discussion of how a shift from salt marsh to mangrove dominance may shape these coastal communities (e.g., Kelleway et al., 2017; Johnston and Gruner, 2018; Smith et al., 2019; Armitage et al., 2020) by including mangrove intraspecific variation as a factor that could influence population resilience at these high-stress range limits.

This research also provides the first documentation of community-genetic effects in a natural mangrove system. Does the genetic similarity rule apply elsewhere across the broad distributional range of mangroves and to further mangrove-associated communities? Experimental plantings demonstrate that mangrove maternal genotypic identity can impact the composition of associated soil microbial communities (Craig, Kennedy, et al., 2020), which 
426 indicates that community-genetic effects can have a broader reach in mangrove systems than the

427 more intimately associated endophytic fungal communities assessed here. Moreover,

428 intraspecific differences in quantitative traits of mangroves, including trichome density (Piovia-

429 Scott, 2011), plant architecture (Silva et al., 2017), and leaf chemistry (Erickson et al., 2004), can

430 affect mangrove-associated communities. Heritable variation in these traits has been identified as

431 a potential factor linking associated communities to host-plant genetics (Whitham et al., 2012).

432 Assessments in additional mangrove-associated communities (of both terrestrial and marine

433 origin) would further our understanding of how host-tree genetic variation may relate to the 434 broader community of organisms associated with these plants, with direct implications for 435 conservation and restoration practices.

437 CONCLUSIONS

438 We found evidence for the genetic similarity rule at an expanding mangrove range limit. This 439 research helps broaden the current scope of community genetics theory by demonstrating that 440 community-genetic effects can occur even at expanding distributional limits where host-plant 441 genetic variation may be limited. Our findings also add to the growing number of diverse 442 systems where associated communities vary with host-plant genetics. As community-level 443 effects of host-plant genetic variation are found to be most prominent in systems dominated by 444 few plant foundation species (Whitham et al., 2006), mangrove forests and their low tree species 445 diversity may prove to be a system ripe for discovery. 
448 This research was funded by a Manchester Metropolitan University studentship to J.P.K. Many

449 thanks to IC Feller and R Feller (and their cast iron skillet) and the Smithsonian Marine Station

450 at Fort Pierce, Florida for logistical support during fieldwork, to N Dix and P Marcum at the

451 Guana Tolomato Matanzas National Estuarine Research Reserve for permission to work at the

452 collection site and provision of monitoring data, to the US Forest Service and the University of

453 Wisconsin-Madison for provision of fungal mock communities for amplicon sequencing, to $\mathrm{H}$

454 Craig for providing information and reagents for microsatellite genotyping, to G Fox for

455 computational assistance, and to the University of Manchester Genomic Technologies Core

456 Facility and F Combe for fragment analysis. Additional thanks to three anonymous reviewers

457 and the Associate Editor whose insightful comments much improved an earlier version of this

458 manuscript. As always, thank you to A Jara Cavieres, C Kennedy, and M Kennedy for

459 unconditional support and big smiles.

460

461 AUTHOR CONTRIBUTIONS

462 J.P.K., R.F.P. and J.K.R. conceived and designed the research. J.P.K. performed field

463 collections, DNA extractions, and host-tree genotyping. R.E.A. performed library preparation

464 and sequencing, and provided analysis tools. R.F.P. and J.K.R. supervised the research. J.P.K.

465 conducted bioinformatics analysis and statistical analyses. J.P.K. wrote the manuscript with input

466 from all co-authors. 
469 Microsatellite genotype data are publicly available on figshare:

470 https://doi.org/10.6084/m9.figshare.14252660.v1. Sequence data are deposited on the NCBI

471 SRA database: https://www.ncbi.nlm.nih.gov/bioproject/PRJNA643237/.

472

473 SUPPORTING INFORMATION

474 Additional Supporting Information may be found online in the supporting information tab for

475 this article.

476 APPENDIX S1 Supplemental Tables:

477 Appendix S1a. Summary of ITS1 gene sequence data sets using only forward sequence reads 478 and using assembled paired-end reads.

479 Appendix S1b. Multiple linear regressions of associated endophytic fungal community diversity 480 (calculated with the raw count data) as a function of the heterozygosity and absolute spatial 481 location of host trees.

482 Appendix S1c. Genetic diversity of 24 nuclear microsatellite loci used for genotyping of 483 Avicennia germinans host trees.

484 Appendix S1d. Endophytic fungal diversity identified with ITS1 gene sequencing. 485

486 APPENDIX S2 Supplemental Figures:

487 Appendix S2a. Rarefaction curves of observed amplicon sequence variants (ASVs) in sampled 488 Avicennia germinans trees.

489 Appendix S2b. Relative abundance across all sequence data of fungal phyla for the forward490 reads data set. 
Appendix S2c. Relative abundance across all sequence data of fungal class for the forward-reads

492

493

494

495

496

497

498

499

500

501

502

503

504

505

506

507

508

509

510

511

512

513

514

515

516

517

518

519

520

521

522

523

524

525

526

data set.

Appendix S2d. Graphical representation of Mantel test and Mantel correlogram between inter-

host genetic distance and inter-host geographic distance.

Appendix S2e. Graphical representation of partial Mantel correlograms between fungal

community dissimilarity, measured with Bray-Curtis dissimilarity and Aitchison distance, and inter-host genetic distance.

\section{LITERATURE CITED}

Alongi, D. M. 2009. Paradigm shifts in mangrove biology. In G. M. E. Perillo, E. Wolanski, D. R. Cahoon, and M. M. Brinson [eds.], Coastal Wetlands An Integrated Ecosystem Approach, 615-640. Elsevier, Amsterdam.

Aparicio, J. M., J. Ortego, and P. J. Cordero. 2006. What should we weigh to estimate heterozygosity, alleles or loci? Molecular Ecology 15: 4659-4665.

Arfi, Y., M. Buée, C. Marchand, A. Levasseur, and E. Record. 2012. Multiple markers pyrosequencing reveals highly diverse and host-specific fungal communities on the mangrove trees Avicennia marina and Rhizophora stylosa. FEMS Microbiology Ecology 79: 433-444.

Armitage, A. R., C. A. Weaver, A. A. Whitt, and S. C. Pennings. 2020. Effects of mangrove encroachment on tidal wetland plant, nekton, and bird communities in the Western Gulf of Mexico. Estuarine, Coastal and Shelf Science: 106767.

Arnold, A. E. 2007. Understanding the diversity of foliar endophytic fungi: progress, challenges, and frontiers. Fungal Biology Reviews 21: 51-66.

Arnold, A. E., and E. A. Herre. 2003. Canopy cover and leaf age affect colonization by tropical fungal endophytes: Ecological pattern and process in Theobroma cacao (Malvaceae). Mycologia 95: 388-398.

Bangert, R. K., G. J. Allan, R. J. Turek, G. M. Wimp, N. Meneses, G. D. Martinsen, P. Keim, and T. G. Whitham. 2006. From genes to geography: a genetic similarity rule for arthropod community structure at multiple geographic scales. Molecular Ecology 15: 4215-4228.

Bangert, R. K., E. V. Lonsdorf, G. M. Wimp, S. M. Shuster, D. Fischer, J. A. Schweitzer, G. J. Allan, et al. 2008. Genetic structure of a foundation species: Scaling community phenotypes from the individual to the region. Heredity 100: 121-131.

Bangert, R. K., R. J. Turek, B. Rehill, G. M. Wimp, J. A. Schweitzer, G. J. Allan, J. K. Bailey, et al. 2006. A genetic similarity rule determines arthropod community structure. Molecular Ecology 15: 1379-1391.

Barbour, M. A., S. Erlandson, K. Peay, B. Locke, E. S. Jules, and G. M. Crutsinger. 2019. Trait 
plasticity is more important than genetic variation in determining species richness of associated communities. Journal of Ecology 107: 350-360.

Barbour, R. C., J. M. O’Reilly-Wapstra, D. W. De Little, G. J. Jordan, D. A. Steane, J. R. Humphreys, J. K. Bailey, et al. 2009. A geographic mosaic of genetic variation within a foundation tree species and its community-level consequences. Ecology 90: 1762-1772.

Binks, R. M., M. Byrne, K. McMahon, G. Pitt, K. Murray, and R. D. Evans. 2019. Habitat discontinuities form strong barriers to gene flow among mangrove populations, despite the capacity for long-distance dispersal. Diversity and Distributions 25: 298-309.

Bonin, A., E. Bellemain, P. B. Eidesen, F. Pompanon, C. Brochmann, and P. Taberlet. 2004. How to track and assess genotyping errors in population genetics studies. Molecular Ecology 13: 3261-3273.

Callahan, B. J., P. J. McMurdie, M. J. Rosen, A. W. Han, A. J. A. Johnson, and S. P. Holmes. 2016. DADA2: high-resolution sample inference from Illumina amplicon data. Nature Methods 13: 581-583.

Campbell, S. A., J. S. Thaler, and A. Kessler. 2013. Plant chemistry underlies herbivoremediated inbreeding depression in nature. Ecology Letters 16: 252-260.

Cavanaugh, K. C., E. M. Dangremond, C. L. Doughty, A. P. Williams, J. D. Parker, M. A. Hayes, W. Rodriguez, and I. C. Feller. 2019. Climate-driven regime shifts in a mangrovesalt marsh ecotone over the past 250 years. Proceedings of the National Academy of Sciences 116: 21602-21608.

Cavanaugh, K. C., J. R. Kellner, A. J. Forde, D. S. Gruner, J. D. Parker, W. Rodriguez, and I. C. Feller. 2014. Poleward expansion of mangroves is a threshold response to decreased frequency of extreme cold events. Proceedings of the National Academy of Sciences 111: 723-727.

Cavanaugh, K. C., J. D. Parker, S. C. Cook-Patton, I. C. Feller, A. P. Williams, and J. R. Kellner. 2015. Integrating physiological threshold experiments with climate modeling to project mangrove species' range expansion. Global Change Biology 21: 1928-1938.

Cerón-Souza, I., E. Bermingham, W. O. McMillan, and F. A. Jones. 2012. Comparative genetic structure of two mangrove species in Caribbean and Pacific estuaries of Panama. BMC Evolutionary Biology 12: 205.

Cerón-Souza, I., E. Rivera-Ocasio, S. M. Funk, and W. O. McMillan. 2006. Development of six microsatellite loci for black mangrove (Avicennia germinans). Molecular Ecology Notes 6: 692-694.

Chao, A., N. J. Gotelli, T. C. Hsieh, E. L. Sander, K. H. Ma, R. K. Colwell, and A. M. Ellison. 2014. Rarefaction and extrapolation with Hill numbers: A framework for sampling and estimation in species diversity studies. Ecological Monographs 84: 45-67.

Charlesworth, D., and J. H. Willis. 2009. The genetics of inbreeding depression. Nature Reviews Genetics 10: 783-796.

Chen, E., J. A. Blaze, R. S. Smith, S. Peng, and J. E. Byers. 2020. Freeze-tolerance of polewardspreading mangrove species weakened by soil properties of resident salt marsh competitor. Journal of Ecology 108: 1725-1737.

Coulon, A. 2010. GENHET: An easy-to-use R function to estimate individual heterozygosity. Molecular Ecology Resources 10: 167-169.

Covarrubias-Pazaran, G., L. Diaz-Garcia, B. Schlautman, W. Salazar, and J. Zalapa. 2016. Fragman: an R package for fragment analysis. BMC Genetics 17: 1-8.

Craig, H., I. C. Feller, and J. K. Rowntree. 2020. Development of additional microsatellite 
primers for the mangrove tree species Avicennia germinans. bioRxiv: 2020.12.14.422622.

Craig, H., J. P. Kennedy, D. J. Devlin, R. D. Bardgett, and J. K. Rowntree. 2020. Effects of maternal genotypic identity and genetic diversity of the red mangrove Rhizophora mangle on associated soil bacterial communities: a field-based experiment. Ecology and Evolution 10: 13957-13967.

Crutsinger, G. M., M. D. Collins, J. A. Fordyce, Z. Gompert, C. C. Nice, and N. J. Sanders. 2006. Plant genotypic diversity predicts community structure and governs an ecosystem process. Science 313: 966-968.

Davies, C., C. J. Ellis, G. R. Iason, and R. A. Ennos. 2014. Genotypic variation in a foundation tree (Populus tremula L.) explains community structure of associated epiphytes. Biology Letters 10: 20140190.

Devaney, J. L., M. Lehmann, I. C. Feller, and J. D. Parker. 2017. Mangrove microclimates alter seedling dynamics at the range edge. Ecology 98: 2513-2520.

Diniz-Filho, J. A. F., T. N. Soares, J. S. Lima, R. Dobrovolski, V. L. Landeiro, M. P. de C. Telles, T. F. Rangel, and L. M. Bini. 2013. Mantel test in population genetics. Genetics and Molecular Biology 36: 475-485.

Elamo, P., M. L. Helander, I. Saloniemi, and S. Neuvonen. 1999. Birch family and environmental conditions affect endophytic fungi in leaves. Oecologia 118: 151-156.

Ellison, A. M., M. S. Bank, B. D. Clinton, E. A. Colburn, K. Elliott, C. R. Ford, D. R. Foster, et al. 2005. Loss of Foundation Species: Consequences for the Structure and Dynamics of Forested Ecosystems. Frontiers in Ecology and the Environment 3: 479-486.

Erickson, A. A., S. S. Bell, and C. J. Dawes. 2004. Does mangrove leaf chemistry help explain crab herbivory patterns? Biotropica 36: 333-343.

Farnsworth, E. 1998. Issues of spatial, taxonomic and temporal scale in delineating links between mangrove diversity and ecosystem function. Global Ecology \& Biogeography Letters 7: 15-25.

Gilbert, G. S., M. Mejía-Chang, and E. Rojas. 2002. Fungal diversity and plant disease in mangrove forests: Salt excretion as a possible defense mechanism. Oecologia 132: 278285.

Giri, C., E. Ochieng, L. L. Tieszen, Z. Zhu, A. Singh, T. Loveland, J. Masek, and N. Duke. 2011. Status and distribution of mangrove forests of the world using earth observation satellite data. Global Ecology and Biogeography 20: 154-159.

Gloor, G. B., J. M. Macklaim, V. Pawlowsky-Glahn, and J. J. Egozcue. 2017. Microbiome datasets are compositional: And this is not optional. Frontiers in Microbiology 8: 2224.

Goslee, S. C., and D. L. Urban. 2007. The ecodist Package for Dissimilarity-based Analysis of Ecological Data. Journal of Statistical Software 22: 1-19.

Gossner, M. M., M. Brändle, R. Brandl, J. Bail, J. Müller, and L. Opgenoorth. 2015. Where is the extended phenotype in the wild? The community composition of arthropods on mature oak trees does not depend on the oak genotype. PLOS ONE 10: e0115733.

Goudet, J. 2002. FSTAT (Version 2.9.3.2): a program to estimate and test gene diversities and fixation indices. URL: http://www2.unil.ch/popgen/softwares.

Griffiths, S. M., M. Galambao, J. Rowntree, I. Goodhead, J. Hall, D. O’Brien, N. Atkinson, and R. E. Antwis. 2020. Complex associations between cross-kingdom microbial endophytes and host genotype in ash dieback disease dynamics. Journal of Ecology 108: 291-309.

Hansson, B., and L. Westerberg. 2002. On the correlation between heterozygosity and fitness in natural populations. Molecular Ecology 11: 2467-2474. 
Hill, M. O. 1973. Diversity and evenness: a unifying notation and its consequences. Ecology 54: 427-432.

Hughes, A. R., and J. J. Stachowicz. 2009. Ecological impacts of genotypic diversity in the clonal seagrass Zostera marina. Ecology 90: 1412-1419.

Johnson, M. T. J., M. J. Lajeunesse, and A. A. Agrawal. 2006. Additive and interactive effects of plant genotypic diversity on arthropod communities and plant fitness. Ecology Letters 9: 24-34.

Johnston, C. A., and D. S. Gruner. 2018. Marine fauna sort at fine resolution in an ecotone of shifting wetland foundation species. Ecology 99: 2546-2557.

Jormalainen, V., M. Danelli, K. Gagnon, H. Hillebrand, E. Rothäusler, J. P. Salminen, and J. Sjöroos. 2017. Genetic variation of a foundation rockweed species affects associated communities. Ecology 98: 2940-2951.

Kagiya, S., M. Yasugi, H. Kudoh, A. J. Nagano, and S. Utsumi. 2018. Does genomic variation in a foundation species predict arthropod community structure in a riparian forest? Molecular Ecology 27: 1284-1295.

Kangas, P. C., and A. E. Lugo. 1990. The distribution of mangroves and saltmarsh in Florida. Tropical Ecology 31: 32-39.

Kelleway, J. J., K. Cavanaugh, K. Rogers, I. C. Feller, E. Ens, C. Doughty, and N. Saintilan. 2017. Review of the ecosystem service implications of mangrove encroachment into salt marshes. Global Change Biology 23: 3967-3983.

Kembel, S. W., and R. C. Mueller. 2014. Plant traits and taxonomy drive host associations in tropical Phyllosphere fungal communities. Botany 92: 303-311.

Kennedy, J. P., E. M. Dangremond, M. A. Hayes, R. F. Preziosi, J. K. Rowntree, and I. C. Feller. 2020. Hurricanes overcome migration lag and shape intraspecific genetic variation beyond a poleward mangrove range limit. Molecular Ecology 29: 2583-2597.

Kennedy, J. P., L. Garavelli, N. K. Truelove, D. J. Devlin, S. J. Box, L. M. Chérubin, and I. C. Feller. 2017. Contrasting genetic effects of red mangrove (Rhizophora mangle L.) range expansion along West and East Florida. Journal of Biogeography 44: 335-347.

Kennedy, J. P., R. F. Preziosi, J. K. Rowntree, and I. C. Feller. 2020. Is the central-marginal hypothesis a general rule? Evidence from three distributions of an expanding mangrove species, Avicennia germinans (L.) L. Molecular Ecology 29: 704-719.

Kennedy, J. P., J. M. Sammy, J. K. Rowntree, and R. F. Preziosi. 2021. Mating system variation in neotropical black mangrove, Avicennia germinans, at three spatial scales towards an expanding northern distributional limit. Estuarine, Coastal and Shelf Science 248: 106754.

Koide, R. T., K. D. Ricks, and E. R. Davis. 2017. Climate and dispersal influence the structure of leaf fungal endophyte communities of Quercus gambelii in the eastern Great Basin, USA. Fungal Ecology 30: 19-28.

Lahti, L., S. Shetty, T. Blake, and J. Salojarvi. 2017. Tools for microbiome analysis in R. Version 2.1.26. URL: http://microbiome.github.com/microbiome.

Lamit, L. J., M. K. Lau, R. Reese Næsborg, T. Wojtowicz, T. G. Whitham, and C. A. Gehring. 2015. Genotype variation in bark texture drives lichen community assembly across multiple environments. Ecology 96: 960-971.

Lamit, L. J., M. K. Lau, C. M. Sthultz, S. C. Wooley, T. G. Whitham, and C. A. Gehring. 2014. Tree genotype and genetically based growth traits structure twig endophyte communities. American Journal of Botany 101: 467-478.

Lee, N. L. Y., D. Huang, Z. B. R. Quek, J. N. Lee, and B. J. Wainwright. 2020. Distinct fungal 
communities associated with different organs of the mangrove Sonneratia alba in the Malay Peninsula. IMA Fungus 11: 17.

Lee, N. L. Y., D. Huang, Z. B. R. Quek, J. N. Lee, and B. J. Wainwright. 2019. Mangroveassociated fungal communities are differentiated by geographic location and host structure. Frontiers in Microbiology 10: 2456.

Lee, S. Y., J. H. Primavera, F. Dahdouh-Guebas, K. McKee, J. O. Bosire, S. Cannicci, K. Diele, et al. 2014. Ecological role and services of tropical mangrove ecosystems: A reassessment. Global Ecology and Biogeography 23: 726-743.

Legendre, P., M. J. Fortin, and D. Borcard. 2015. Should the Mantel test be used in spatial analysis? Methods in Ecology and Evolution 6: 1239-1247.

Lonard, R. I., F. W. Judd, K. Summy, H. DeYoe, and R. Stalter. 2017. The Biological Flora of Coastal Dunes and Wetlands: Avicennia germinans (L.) L. Journal of Coastal Research 33: 191-207.

Martin, M. 2011. Cutadapt removes adapter sequences from high-throughput sequencing reads. EMBnet.journal 17: 10-12.

McMurdie, P. J., and S. Holmes. 2013. Phyloseq: An R Package for Reproducible Interactive Analysis and Graphics of Microbiome Census Data. PLoS ONE 8: e61217.

McMurdie, P. J., and S. Holmes. 2014. Waste Not, Want Not: Why Rarefying Microbiome Data Is Inadmissible. PLoS Computational Biology 10: e1003531.

Mori, G. M., M. I. Zucchi, I. Sampaio, and A. P. Souza. 2010. Microsatellites for the mangrove tree Avicennia germinans (Acanthaceae): Tools for hybridization and mating system studies. American Journal of Botany 97: 79-81.

Nagelkerken, I., S. J. M. Blaber, S. Bouillon, P. Green, M. Haywood, L. G. Kirton, J. O. Meynecke, et al. 2008. The habitat function of mangroves for terrestrial and marine fauna: A review. Aquatic Botany 89: 155-185.

Nettel, A., F. Rafii, and R. S. Dodd. 2005. Characterization of microsatellite markers for the mangrove tree Avicennia germinans L. (Avicenniaceae). Molecular Ecology Notes 5: 103105.

Nguyen, N. H., D. Smith, K. Peay, and P. Kennedy. 2015. Parsing ecological signal from noise in next generation amplicon sequencing. New Phytologist 205: 1389-1393.

Nilsson, R. H., K. H. Larsson, A. F. S. Taylor, J. Bengtsson-Palme, T. S. Jeppesen, D. Schigel, P. Kennedy, et al. 2019. The UNITE database for molecular identification of fungi: Handling dark taxa and parallel taxonomic classifications. Nucleic Acids Research 47: D259-D264.

Ochoa-Zavala, M., J. P. Jaramillo-Correa, D. Piñero, A. Nettel-Hernanz, and J. Núñez-Farfán. 2019. Contrasting colonization patterns of black mangrove (Avicennia germinans (L.) L.) gene pools along the Mexican coasts. Journal of Biogeography 46: 884-898.

van Oosterhout, C., W. F. Hutchinson, D. P. M. Wills, and P. Shipley. 2004. MICROCHECKER: Software for identifying and correcting genotyping errors in microsatellite data. Molecular Ecology Notes 4: 535-538.

Osland, M. J., L. C. Feher, K. T. Griffith, K. C. Cavanaugh, N. M. Enwright, R. H. Day, C. L. Stagg, et al. 2017. Climatic controls on the global distribution, abundance, and species richness of mangrove forests. Ecological Monographs 87: 341-359.

Osland, M. J., L. C. Feher, J. López-Portillo, R. H. Day, D. O. Suman, J. M. Guzmán Menéndez, and V. H. Rivera-Monroy. 2018. Mangrove forests in a rapidly changing world: Global change impacts and conservation opportunities along the Gulf of Mexico coast. Estuarine, Coastal and Shelf Science 214: 120-140. 
Palmer, J. M., M. A. Jusino, M. T. Banik, and D. L. Lindner. 2018. Non-biological synthetic spike-in controls and the AMPtk software pipeline improve mycobiome data. PeerJ 6: e4925.

Pan, J. J., A. M. Baumgarten, and G. May. 2008. Effects of host plant environment and Ustilago maydis infection on the fungal endophyte community of maize (Zea mays). New Phytologist 178: 147-156.

Pauvert, C., M. Buée, V. Laval, V. Edel-Hermann, L. Fauchery, A. Gautier, I. Lesur, et al. 2019. Bioinformatics matters: The accuracy of plant and soil fungal community data is highly dependent on the metabarcoding pipeline. Fungal Ecology 41: 23-33.

Peakall, R., and P. E. Smouse. 2012. GenAlEx 6.5: Genetic analysis in Excel. Population genetic software for teaching and research - an update. Bioinformatics 28: 2537-2539.

Pecl, G. T., M. B. Araújo, J. D. Bell, J. Blanchard, T. C. Bonebrake, I. C. Chen, T. D. Clark, et al. 2017. Biodiversity redistribution under climate change: Impacts on ecosystems and human well-being. Science 355: eaai9214.

Pil, M. W., M. R. T. Boeger, V. C. Muschner, M. R. Pie, A. Ostrensky, and W. A. Boeger. 2011. Postglacial north-south expansion of populations of Rhizophora mangle (Rhizophoraceae) along the Brazilian coast revealed by microsatellite analysis. American Journal of Botany 98: 1031-1039.

Piovia-Scott, J. 2011. Plant phenotype influences the effect of ant mutualists on a polymorphic mangrove. Journal of Ecology 99: 327-334.

Pironon, S., G. Papuga, J. Villellas, A. L. Angert, M. B. García, and J. D. Thompson. 2017. Geographic variation in genetic and demographic performance: new insights from an old biogeographical paradigm. Biological Reviews 92: 1877-1909.

Pohjanmies, T., A. J. M. Tack, P. Pulkkinen, S. Elshibli, P. Vakkari, and T. Roslin. 2015. Genetic diversity and connectivity shape herbivore load within an oak population at its range limit. Ecosphere 6: 101.

Porras-Alfaro, A., and P. Bayman. 2011. Hidden Fungi, Emergent Properties: Endophytes and Microbiomes. Annual Review of Phytopathology 49: 291-315.

Quinn, T. P., I. Erb, M. F. Richardson, and T. M. Crowley. 2018. Understanding sequencing data as compositions: An outlook and review. Bioinformatics 34: 2870-2878.

R Core Team. 2020. R: A language and environment for statistical computing. R Foundation for Statistical Computing, Vienna, Austria. URL: https://R-project.org.

Raffard, A., F. Santoul, J. Cucherousset, and S. Blanchet. 2019. The community and ecosystem consequences of intraspecific diversity: a meta-analysis. Biological Reviews 94: 648-661.

Ricks, K. D., and R. T. Koide. 2019. Biotic filtering of endophytic fungal communities in Bromus tectorum. Oecologia 189: 993-1003.

Rodriguez, R. J., R. S. Redman, and J. M. Henson. 2004. The role of fungal symbioses in the adaptation of plants to high stress environments. Mitigation and Adaptation Strategies for Global Change 9: 261-272.

Rodriguez, W., I. C. Feller, and K. C. Cavanaugh. 2016. Spatio-temporal changes of a mangrove-saltmarsh ecotone in the northeastern coast of Florida, USA. Global Ecology and Conservation 7: 245-261.

De Ryck, D. J. R., N. Koedam, T. Van der Stocken, R. M. van der Ven, J. Adams, and L. Triest. 2016. Dispersal limitation of the mangrove Avicennia marina at its South African range limit in strong contrast to connectivity in its core East African region. Marine Ecology Progress Series 545: 123-134. 
Schwarz, G. 1978. Estimating the dimension of a model. Annals of Statistics 6: 461-464. Silva, L. L., R. C. O. Santos, and M. E. B. Fernandes. 2017. Linking Avicennia germinans (Acanthaceae) architecture to gall richness and abundance in Brazilian Amazon mangroves. Biotropica 49: 784-791.

Smith, D. P., and K. G. Peay. 2014. Sequence depth, not PCR replication, improves ecological inference from next generation DNA sequencing. PLoS ONE 9: e90234.

Smith, R. S., T. Z. Osborne, I. C. Feller, and J. E. Byers. 2019. Detrital traits affect substitutability of a range-expanding foundation species across latitude. Oikos 128: 13671380.

Smouse, P. E., and R. Peakall. 1999. Spatial autocorrelation analysis of individual multiallele and multilocus genetic structure. Heredity 82: 561-573.

Sobrado, M. A., and E. D. Greaves. 2000. Leaf secretion composition of the mangrove species Avicennia germinans (L.) in relation to salinity: A case study by using total-reflection X-ray fluorescence analysis. Plant Science 159: 1-5.

Soldan, R., F. Mapelli, E. Crotti, S. Schnell, D. Daffonchio, R. Marasco, M. Fusi, et al. 2019. Bacterial endophytes of mangrove propagules elicit early establishment of the natural host and promote growth of cereal crops under salt stress. Microbiological Research 223-225: 33-43.

de Souza Sebastianes, F. L., A. S. Romão-Dumaresq, P. T. Lacava, R. Harakava, J. L. Azevedo, I. S. De Melo, and A. A. Pizzirani-Kleiner. 2013. Species diversity of culturable endophytic fungi from Brazilian mangrove forests. Current Genetics 59: 153-166.

Stevenson, C. R., C. Davies, and J. K. Rowntree. 2017. Biodiversity in agricultural landscapes: The effect of apple cultivar on epiphyte diversity. Ecology and Evolution 7: 1250-1258.

Suárez, N., and E. Medina. 2008. Salinity effects on leaf ion composition and salt secretion rate in Avicennia germinans (L.) L. Brazilian Journal of Plant Physiology 20: 131-140.

Szulkin, M., N. Bierne, and P. David. 2010. Heterozygosity-fitness correlations: A time for reappraisal. Evolution 64: 1202-1217.

Tack, A. J. M., O. Ovaskainen, P. Pulkkinen, and T. Roslin. 2010. Spatial location dominates over host plant genotype in structuring an herbivore community. Ecology 91: 2660-2672.

Tomlinson, P. B. 1986. The Botany of Mangroves. Cambridge University Press, Cambridge, UK. Tovar-Sánchez, E., L. Valencia-Cuevas, E. Castillo-Mendoza, P. Mussali-Galante, R. V PérezRuiz, and A. Mendoza. 2013. Association between individual genetic diversity of two oak host species and canopy arthropod community structure. European Journal of Forest Research 132: 165-179.

U'Ren, J. M., J. M. Riddle, J. T. Monacell, I. Carbone, J. Miadlikowska, and A. E. Arnold. 2014. Tissue storage and primer selection influence pyrosequencing-based inferences of diversity and community composition of endolichenic and endophytic fungi. Molecular Ecology Resources 14: 1032-1048.

UNITE Community. 2019. UNITE general FASTA release for Fungi 2. Version 18.11.2018. UNITE Community. URL: https://doi.org/10.15156/BIO/786353.

Valencia-Cuevas, L., P. Mussali-Galante, Z. Cano-Santana, J. Pujade-Villar, A. EquihuaMartínez, and E. Tovar-Sánchez. 2018. Genetic variation in foundation species governs the dynamics of trophic interactions. Current Zoology 64: 13-22.

Valkama, E., J. Koricheva, J. P. Salminen, M. Helander, I. Saloniemi, K. Saikkonen, and K. Pihlaja. 2005. Leaf surface traits: Overlooked determinants of birch resistance to herbivores and foliar micro-fungi? Trees - Structure and Function 19: 191-197. 
Vanegas, J., A. Muñoz-García, K. A. Pérez-Parra, I. Figueroa-Galvis, O. Mestanza, and J. Polanía. 2019. Effect of salinity on fungal diversity in the rhizosphere of the halophyte Avicennia germinans from a semi-arid mangrove. Fungal Ecology 42: 100855.

Vega, F. E., A. Simpkins, M. C. Aime, F. Posada, S. W. Peterson, S. A. Rehner, F. Infante, et al. 2010. Fungal endophyte diversity in coffee plants from Colombia, Hawai'i, Mexico and Puerto Rico. Fungal Ecology 3: 122-138.

White, T. J., T. Bruns, S. Lee, and J. Taylor. 1990. Amplification and direct sequencing of fungal ribosomal RNA genes for phylogenetics. In M. A. Innis, D. H. Gefland, J. J. Sninsky, and T. J. White [eds.], PCR protocols: A guide to method and applications, 315-322. Academic Press, San Diego, CA.

Whitham, T. G., J. K. Bailey, J. A. Schweitzer, S. M. Shuster, R. K. Bangert, C. J. Leroy, E. V. Lonsdorf, et al. 2006. A framework for community and ecosystem genetics: From genes to ecosystems. Nature Reviews Genetics 7: 510-523.

Whitham, T. G., C. A. Gehring, L. J. Lamit, T. Wojtowicz, L. M. Evans, A. R. Keith, and D. S. Smith. 2012. Community specificity: life and afterlife effects of genes. Trends in Plant Science 17: 271-281.

Whitham, T. G., W. P. Young, G. D. Martinsen, C. A. Gehring, J. A. Schweitzer, S. M. Shuster, G. M. Wimp, et al. 2003. Community and ecosystem genetics: a consequence of the extended phenotype. Ecology 84: 559-573.

Wimp, G. M., W. P. Young, S. A. Woolbright, G. D. Martinsen, P. Keim, and T. G. Whitham. 2004. Conserving plant genetic diversity for dependent animal communities. Ecology Letters 7: 776-780.

Younginger, B. S., and D. J. Ballhorn. 2017. Fungal endophyte communities in the temperate fern polystichum munitum show early colonization and extensive temporal turnover. American Journal of Botany 104: 1188-1194.

Zytynska, S. E., M. F. Fay, D. Penney, and R. F. Preziosi. 2011. Genetic variation in a tropical tree species influences the associated epiphytic plant and invertebrate communities in a complex forest ecosystem. Philosophical Transactions of the Royal Society B: Biological Sciences 366: 1329-1336. 
833 Table 1. Multiple linear regressions of alpha diversity of associated endophytic fungal

834 communities as a function of the heterozygosity and absolute spatial location of host trees. Alpha

835 diversity of associated communities was calculated with Hill numbers at the scales of $q=0$

836 (species richness), $\mathrm{q}=1$ (exponential of Shannon index), and $\mathrm{q}=2$ (inverse of Simpson index),

837 which put more weight on abundant species as the value of q increases. Bold values indicate

838 statistical significance $(\mathrm{p}<0.05)$.

\begin{tabular}{llcccc} 
Response & Predictor & Estimate & SE & $\mathbf{t}$ & p \\
\hline $\mathrm{q}=0$ & Heterozygosity & -0.01 & 0.16 & -0.12 & 0.909 \\
& Longitude & 0.37 & 0.18 & 2.10 & $\mathbf{0 . 0 4 3}$ \\
& Latitude & -0.26 & 0.18 & -1.47 & 0.150 \\
\hline $\mathrm{q}=1$ & Heterozygosity & -0.08 & 0.15 & -0.55 & 0.588 \\
& Longitude & 0.47 & 0.17 & 2.76 & $\mathbf{0 . 0 0 9}$ \\
& Latitude & -0.11 & 0.17 & -0.65 & 0.520 \\
\hline $\mathrm{q}=2$ & Heterozygosity & -0.10 & 0.15 & -0.66 & 0.515 \\
& Longitude & 0.46 & 0.17 & 2.74 & $\mathbf{0 . 0 0 9}$ \\
& Latitude & -0.05 & 0.17 & -0.29 & 0.772
\end{tabular}




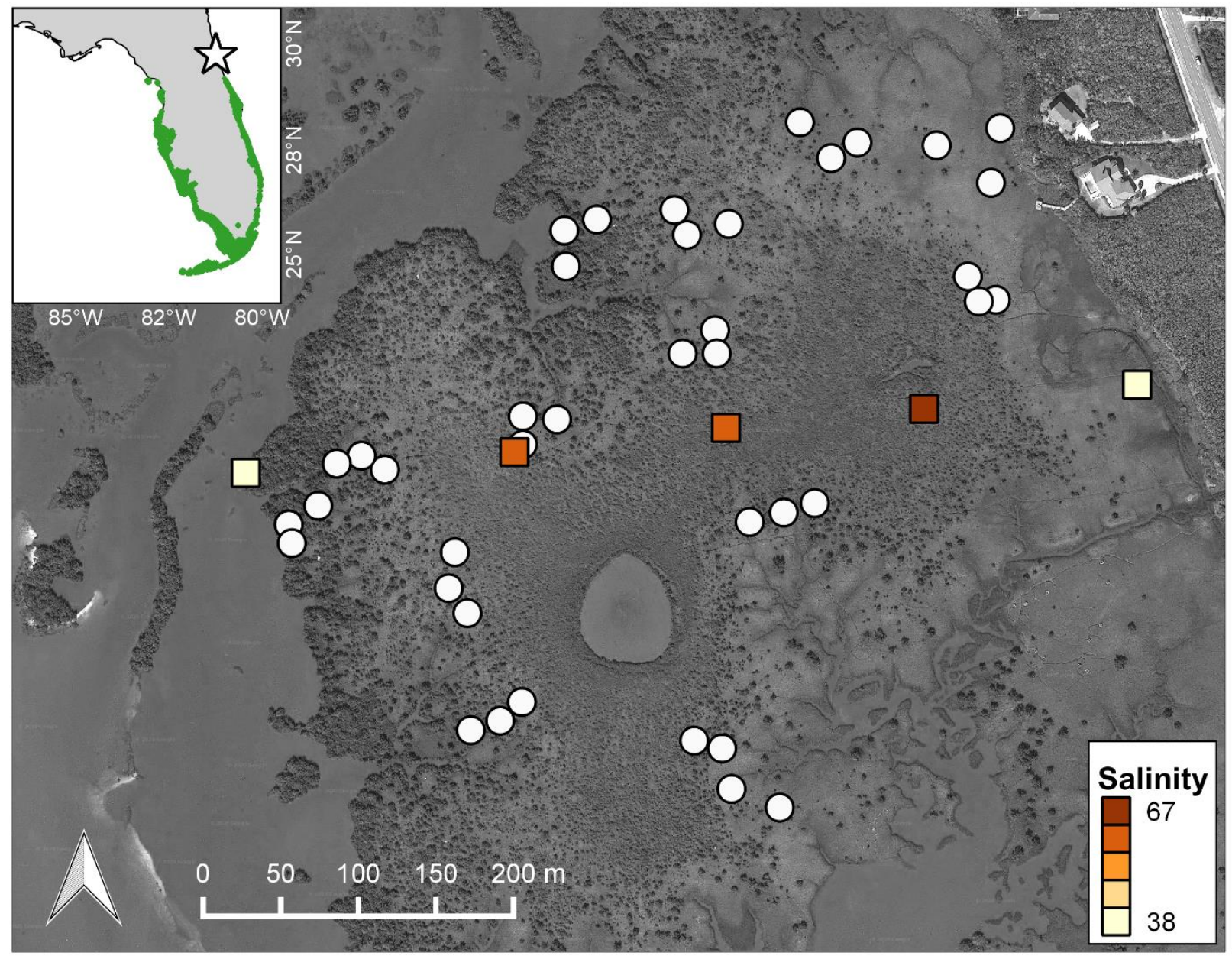

841 Figure 1. Collection site at the Atlantic Florida, USA, northern distributional limit of Avicennia

842 germinans with locations of the 40 sampled A. germinans trees. This site is flanked by a brackish 843 lagoon to the west and a fringe of terrestrial forest to the east. Soil salinities (\%) are mean values 844 measured between September and November (2012-2017) (Guana Tolomato Matanzas National 845 Estuarine Research Reserve, unpublished data). Upper panel shows the location of the collection 846 site (with a star) and the Florida mangrove distribution in green (Giri et al., 2011). 
Mantel Tests

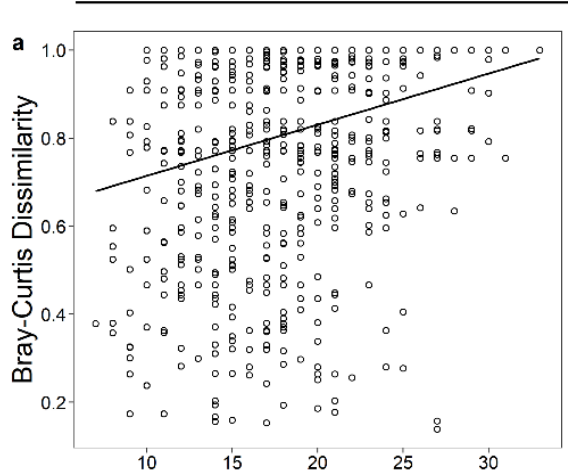

io $\quad 15 \quad 20 \quad 25 \quad 30$

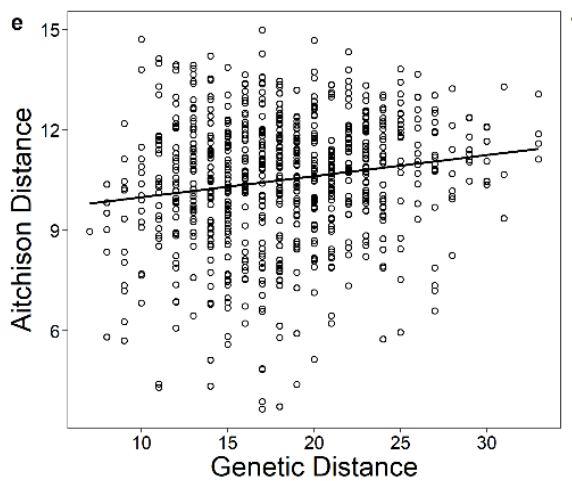

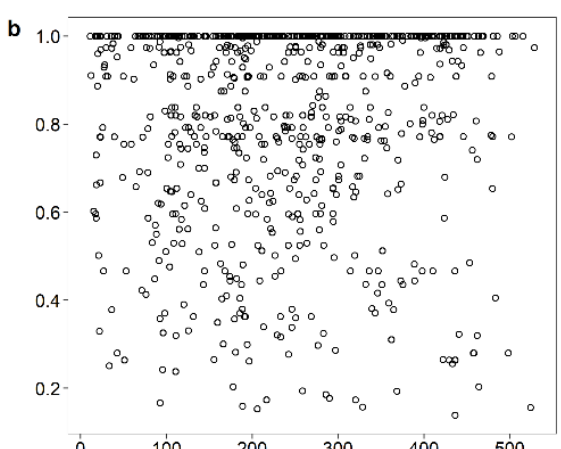

$$
0
$$

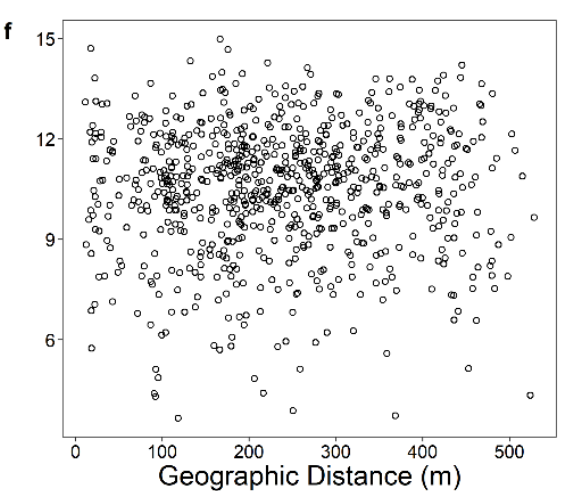

Mantel Correlograms
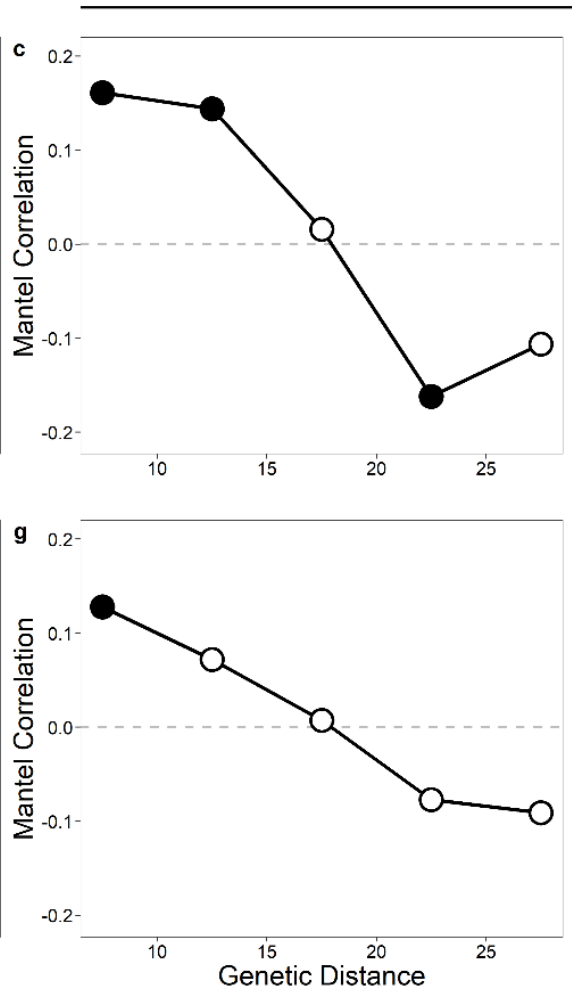

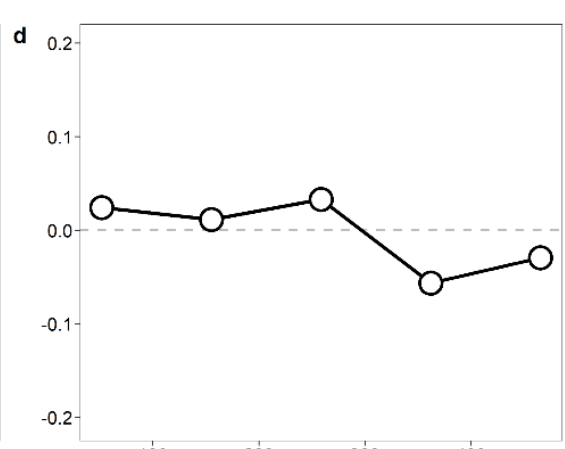

$100-200-300-400$

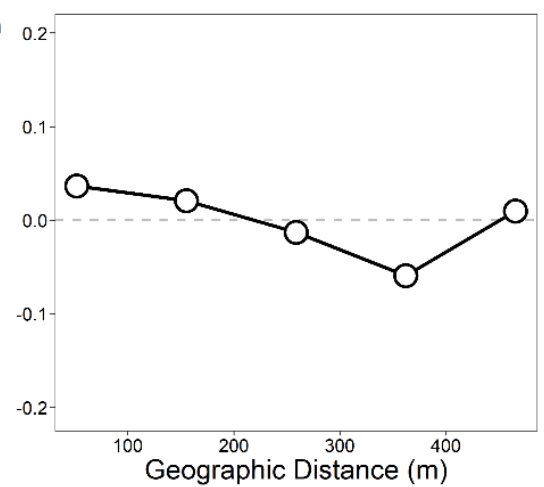

848 Figure 2. Genetically-similar mangrove host trees harboured similar associated endophytic fungal communities, independent of

849 geographic distances among these host trees. Panels show graphical representations of the relationships between fungal community

850 dissimilarity (measured with Bray-Curtis dissimilarity and Aitchison distance) and each of the two predictor variables (inter-host

851 genetic distance and inter-host geographic distance) across all mangrove host trees (Mantel tests) and at five distance classes (Mantel

852 correlograms). Statistically significant ( $\mathrm{p}$ <.05) correlations between fungal community dissimilarity and inter-host genetic

853 distance(s) are depicted with solid lines for Mantel tests and with black circles for Mantel correlograms. 

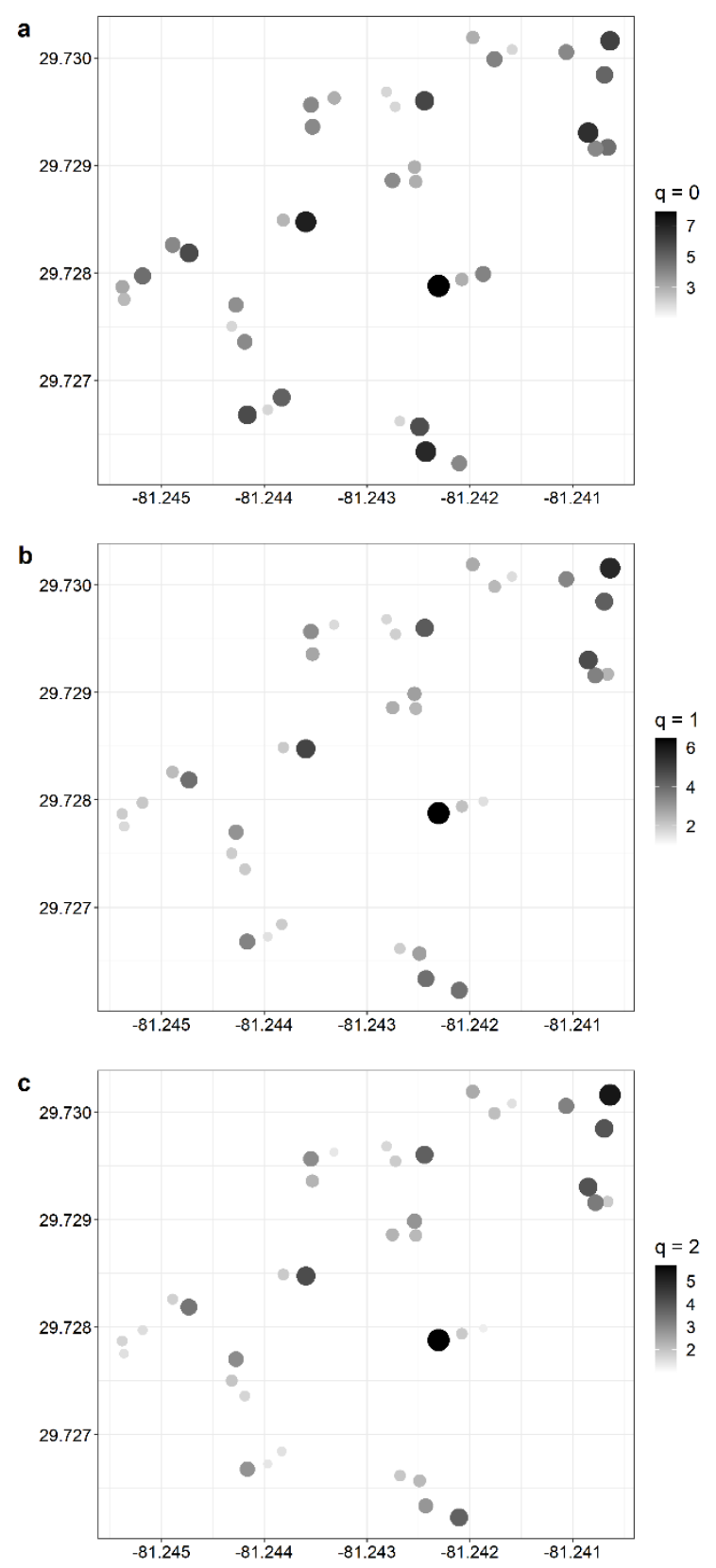

855 Figure 3. Spatial distribution of the alpha diversity of associated endophytic fungal communities 856 within 40 Avicennia germinans trees across a collection site at the northern distributional limit of 857 this species. Alpha diversity was calculated with Hill numbers at the scales of (a) q=0 (species 858 richness), (b) q=1 (exponential of Shannon index), and (c) q=2 (inverse of Simpson index), 859 which put more weight on abundant species as the value of q increases. In the figure, values of 860 fungal alpha diversity for each tree increase with colour (from white to black) and with the size 861 of the data point. 